\title{
Determinan Keberhasilan Pemberian Air Susu Ibu Eksklusif
}

\section{Determinants of the Successful of Exclusive Breast Feeding}

\author{
Bayu Kurniawan \\ Rumah Sakit Muhammadiyah Lamongan
}

\begin{abstract}
ABSTRAK
Pemberian ASI eksklusif secara nasional pada tahun 2010-2012 hanya 33,6-35\%. Menyusui adalah perilaku kesehatan multidimensional yang dipengaruhi oleh interaksi dari faktor sosial, demografi, biologi, pre/postnatal, dan psikologi. Penelitian dilakukan untuk mengidentifikasi faktor determinan pemberian ASI eksklusif. Cross sectional retrospective study dilakukan di Instalasi Rawat Jalan dan Rawat Inap RS Muhammadiyah Lamongan pada Januari-Maret 2013. Sebanyak 150 ibu dari anak berusia 6-24 bulan dilibatkan sebagai sampel penelitian yang diambil dengan metode purposive quota sampling. Kuesioner digunakan sebagai instrumen penelitian untuk mengevaluasi faktor sosiodemografik, pre/postnatal, dan psikososial terhadap keberhasilan ibu memberikan ASI eksklusif dengan uji korelasi Spearman. Hasil menunjukkan angka ASI eksklusif sebesar 35,3\% dengan masa pemberian terbanyak sampai usia 4 bulan. Permasalahan menyusui $(r s=0,249, p=0,002)$ dan kunjungan ke klinik laktasi, keinginan $(r s=0,306, p=0,000)$, keyakinan ( $r s=0,306, p=0,000)$, dan persepsi ibu tentang kepuasan bayi saat menyusu ( $r s=0,263, p=0,001$ ), dukungan suami $(r s=0,318, p=0,000)$ dan orang tua $(r s=0,290, p=0,000)$ mendorong keberhasilan pemberian ASI eksklusif. Usia tua ( $r s=-$ $0,196, p=0,016)$, ibu bekerja ( $r s=-0,170, p=0,038)$, pemberian susu formula di instansi pelayanan kesehatan $(r s=-0,335$, $p=0,000)$, MPASI dini pada bayi usia $<6$ bulan $(r s=-0,710, p=0,000)$, dan pemakaian empeng (pacifier) $(r s=-0,189, p=0,020)$ menjadi faktor yang menghalangi keberhasilan pemberian ASI eksklusif. Pemberian MPASI dini merupakan faktor determinan negative yang paling kuat, sedangkan keyakinan dan persepsi ibu yang kuat tentang menyusui merupkan faktor determinan positif yang paling kuat.
\end{abstract}

Kata Kunci: ASI eksklusif, pre/post natal, psikososial, sosiodemografi

\begin{abstract}
From 2010-2012, the number of Exclusive Breast Feeding nationally only 33,6-35\%. Breastfeeding is a multidimensional health behavior influenced by some factors such as social, demography, biology, pre/post-natal and psychology. This research aims to identify determinant factors that influence exclusive breast feeding. Cross sectional retrospective study conducted at outpatient and inpatient unit of Muhammadiyah Lamongan Hospital on January-March 2013. Research subjects are 150 mothers of 6-24 months children chosen with purposive quota sampling method. Questionnaire used as research instrument to evaluate social-demography, pre/post-natal and psychosocial factors of the successful of exclusive breastfeeding then tested with spearman correlation test. The result showed exclusive breastfeeding is 35,3\% with the duration of 4 months. Breastfeeding problem ( $r s=0,249, p=0,002)$ and lactation clinic visitation, willingness ( $r s=0,306$, $p=0,000)$, believe $(r s=0,306, p=0,000)$, and mother perception on baby's satisfaction on breastfeeding $(r s=0,263, p=0,001)$, husband's support $(r s=0,318, p=0,000)$ and parents $(r s=0,290, p=0,000)$ encourage the successful of exclusive breastfeeding. Older age ( $r s=-0,196, p=0,016)$, working mother $(r s=-0,170, p=0,038)$, formula given in the health services ( $r s=-0,335, p=0,000)$, breastfeeding companion food (MPASI) for baby <6months ( $r s=-0,710, p=0,000)$, pacifier use ( $r s=-$ $0,189, p=0,020$ ) are becoming the restrain factors for exclusive breastfeeding. Early breastfeeding companion is the strongest negative determinant; in the other hand, believed and strong perception of mother on breastfeeding is the strongest positive determinant.
\end{abstract}

Keywords: Exclusive breastfeeding, pre/postnatal, psychosocial, socio-demography

Jurnal Kedokteran Brawijaya, Vol. 27, No. 4, Agustus 2013; Korespondensi: Bayu Kurniawan. Rumah Sakit Muhammadiyah Lamongan, Jl. Jaksa Agung Suprapto No. 76 Lamongan 62215 Tel. (0322) 322834 Email: bayukurniawanmd@gmail.com 


\section{PENDAHULUAN}

Air susu ibu (ASI) adalah makanan terbaik bagi bayi sampai usia 6 bulan. World Health Organization (WHO) mengeluarkan rekomendasi tentang pemberian ASI eksklusif (bayi hanya diberikan ASI tanpa cairan atau makanan lain, kecuali suplemen vitamin, mineral, dan atau obat-obatan untuk keperluan medis) sampai bayi berusia 6 bulan, dan dilanjutkan pemberian ASI sampai dua tahun pertama kehidupannya (1). Hasil rapid assesment Kementerian Kesehatan Tahun 2011, menemukan banyak rumah sakit pemerintah dan swasta yang menerima sponsor dan hadiah dari perusahaan susu formula, hal ini tentunya melemahkan upaya peningkatan cakupan keberhasilan ASI eksklusif di Indonesia. Keberhasilan pemberian ASI eksklusif secara nasional hanya 33,6\%, dan 35\% menurut WHO Global Data Bank 2012, sehingga peran aktif dari seluruh lapisan masyarakat mutlak diperlukan untuk meningkatkan keberhasilan promosi ASI eksklusif di Indonesia (2).

Data riset fasilitas kesehatan dasar 2011 mengungkapkan bahwa baru sekitar 40\% Rumah Sakit yang melaksanakan Rumah Sakit Sayang Ibu dan Bayi sebagai penerapan 10 langkah keberhasilan menyusui (2). Rumah Sakit Muhammadiyah Lamongan telah mengikrarkan diri sebagai rumah sakit sayang ibu dan bayi (baby friendly hospital initiative) hampir dua tahun terakhir. Hal ini merupakan bentuk tanggungjawab RS Muhammadiyah Lamongan berperan aktif mewujudkan millennium development goal tahun 2015 (3).

Menyusui adalah perilaku kesehatan multidimensional yang dipengaruhi oleh interaksi dari faktor-faktor demografi, biologi, psikologi, dan sosial. Faktor-faktor ini ada yang bersifat modificable dan unmodificable. Banyak literatur yang menampilkan hubungan kausal beberapa faktor terhadap keberhasilan ibu memberikan ASI ekslusif, beberapa faktor menampilkan hasil yang inkonsisten terhadap keberhasilan ibu memberikan ASI eksklusif (4). Seringkali variasi hasil ini dipengaruhi oleh faktor sosiodemografi dari penelitian yang dilaksanakan (5). Penelitian ini bertujuan untuk mengetahui hubungan faktor sosiodemografik, pre/post natal, dan psikososial terhadap keberhasilan ibu memberikan ASI eksklusif di RS Muhammadiyah Lamongan.

\section{METODE}

Penelitian ini menggunakan desain cross sectional retrospective study untuk mengetahui faktor determinan keberhasilan pemberian ASI eksklusif di Rumah Sakit Muhammadiyah Lamongan. Pengumpulan data primer dilaksanakan di Instalasi Rawat Jalan dan Rawat Inap RS Muhammadiyah Lamongan pada Januari-Maret 2013. populasi terjangkau adalah ibu ibu dari anak berusia 6-24 bulan yang menjadi pasien rawat jalan dan atau rawat inap di RS Muhammadiyah Lamongan pada periode Januari-Maret 2013. Jumlah sampel penelitian sejumlah 146 responden. Data diuji menggunakan metode analisa bivariate korelasi Spearman menggunakan software SPSS 15.0 for Windows dengan tingkat kemaknaan (confidence interval) sebesar $95 \%(6)$.

\section{HASIL}

Pengumpulan data yang dilakukan selama 8 minggu (Januari-Maret 2013), didapatkan 150 responden yang memenuhi kriteria inklusi (purposive random sampling).
Responden yang berhasil memberikan ASI eksklusif sejumlah 53 orang $(35,3 \%)$ dan 97 orang $(64,7 \%)$. Rata-rata responden memberikan ASI eksklusif sampai usia 4 bulan, dan pemberian ASI (eksklusif ataupun parsial) sampai usia 6 bulan dilakukan oleh 44 orang $(29,3 \%)$. Berdasarkan faktor sosiodemografik (Tabel 1), jumlah terbesar ASI eksklusif didapatkan pada kelompok usia 31-35 tahun $(15,3 \%)$, bertempat tinggal di desa $(22,7 \%)$, dengan tingkat pendidikan tinggi ibu diploma/sarjana pada ibu (23,3\%), dan suami $(22,0 \%)$. Ibu tidak bekerja $(19,3 \%)$, atau mulai kerja setelah persalinan $<6$ bulan sejumlah $(25,9 \%)$, dengan pendapatan keluarga di atas upah minimum regional (UMR) $(26,7 \%)$ merupakan kelompok yang banyak memberikan ASI eksklusif. Usia $(r=-0,196, p=0,016)$ dan status bekerja ibu $(r=-0,170, p=0,039)$ mempunyai korelasi lemah yang signifikan dengan pemberian ASI eksklusif. Semakin muda dan ibu yang bekerja meningkatkan kemungkinan keberhasilan ASI eksklusif.

Tabel 1. Hubungan faktor sosiodemografi dengan keberhasilan ASI eksklusif

\begin{tabular}{|c|c|c|c|c|}
\hline \multirow[t]{2}{*}{ Faktor Sosiodemografi } & \multicolumn{2}{|c|}{$\begin{array}{c}\text { ASI Eksklusif } \\
\text { (\%) }\end{array}$} & \multirow{2}{*}{$\begin{array}{l}\text { Korelasi } \\
\text { Spearman }\end{array}$} & \multirow[t]{2}{*}{$p$} \\
\hline & Ya & Tidak & & \\
\hline Usia & & & $-0,196$ & 0,016 \\
\hline 20-25 tahun & 4,7 & 17,3 & & \\
\hline 26-30 tahun & 12,7 & 26,7 & & \\
\hline 31-35 tahun & 15,3 & 16,7 & & \\
\hline$>36$ tahun & 2,7 & 4,0 & & \\
\hline Tempat tinggal & & & $-0,072$ & 0,382 \\
\hline Desa & 22,7 & 46 & & \\
\hline Kota & 12,7 & 18,7 & & \\
\hline Tingkat pendidikan ibu & & & $-0,041$ & 0,625 \\
\hline Tamat SD & 0 & 3,3 & & \\
\hline Tamat SMP & 2,7 & 3,3 & & \\
\hline Tamat SMA & 9,3 & 17,3 & & \\
\hline Diploma/Sarjana & 23,3 & 40,7 & & \\
\hline Tingkat pendidikan suami & & & $-0,156$ & 0,057 \\
\hline Tamat SD & 0 & 3,3 & & \\
\hline Tamat SMP & 2,0 & 4,7 & & \\
\hline Tamat SMA & 11,3 & 26,0 & & \\
\hline Diploma/Sarjana & 22 & 30,7 & & \\
\hline Status pekerjaan ibu & & & $-0,170$ & 0,038 \\
\hline Bekerja & 16,6 & 40,7 & & \\
\hline Tidak bekerja & 19,3 & 24,0 & & \\
\hline Mula kerja setelah persalinan & & & 0,104 & 0,343 \\
\hline Kurang dari 6 & 25,9 & 60,0 & & \\
\hline Bulan & 2,4 & 11,8 & & \\
\hline Lebih dari 6 Bulan & & & & \\
\hline Tingkat pendapatan keluarga & & & 0,021 & 0,800 \\
\hline Di bawah UMR & 8,7 & 14,7 & & \\
\hline Di atas UMR & 26,7 & 50 & & \\
\hline
\end{tabular}

Responden yang memberikan ASI eksklusif berdasarkan faktor pre/post natal, jumlah terbesar didapatkan pada kelompok yang sering mendapatkan penyuluhan ASI $(14,7 \%)$, primipara $(18,0 \%)$, tidak memilki riwayat penyulit laktasi (18,7\%), melakukan antenatal care (ANC) ke dokter $(21,3 \%)$, riwayat persalinan normal $(21,3 \%)$, riwayat tempat persalinan di rumah sakit $(19,3 \%)$, penolong persalinannya oleh tenaga bidan $(18,0 \%)$, non-bayi berat lahir rendah (BBLR) $(34,0 \%)$, tidak melaksanakan inisiasi menyusui dini (IMD) $(20,0 \%)$, rawat gabung $(26,7 \%)$, tidak memiliki riwayat pemberian susu formula setelah persalinan $(24,0 \%)$, tidak pernah rawat inap saat anak berusia 0-6 bulan $(30,7 \%)$, tidak pernah memiliki permasalahan menyusui $(24,0 \%)$, tidak memberikan makanan pendamping ASI (MPASI) dini (35,3\%), dan tidak 
didapatkan riwayat pemakaian empeng (pacifier) (34,7\%). Pemberian MPASI sebelum usia 6 bulan merupakan faktor yang mempunyai korelasi negatif kuat dan signifikan ( $r=-$ $0,710, p<0.001)$. Faktor pre/post natal lain yang juga mempunyai korelasi negatif lemah namun signifikan adalah pemberian susu formula setelah persalinan ( $r=-$ $0,335, p<0,001)$, permasalahan saat menyusui $(r=0,249$, $p=0,002)$ dan pemakaian empeng $(r=-0,189, p=0,02)$.

Tabel 2. Hubungan faktor pre/post natal dengan keberhasilan ASI eksklusif

\begin{tabular}{|c|c|c|c|c|}
\hline \multirow[t]{2}{*}{ Faktor Pre/post natal } & \multicolumn{2}{|c|}{$\begin{array}{l}\text { ASI Eksklusif } \\
(\%)\end{array}$} & \multirow{2}{*}{$\begin{array}{l}\text { Korelasi } \\
\text { Spearman }\end{array}$} & \multirow[t]{2}{*}{ p } \\
\hline & Ya & Tidak & & \\
\hline Penyuluhan ASI eksklusif & & & $-0,110$ & 0,181 \\
\hline Tidak Pernah & 11,3 & 27,3 & & \\
\hline Jarang & 9,3 & 16,7 & & \\
\hline Sering & 14,7 & 20,7 & & \\
\hline Paritas & & & $-0,85$ & 0,299 \\
\hline Primipara & 18 & 38,7 & & \\
\hline Multipara & 17,3 & 26,0 & & \\
\hline Laktasi sebelumnya & & & 0,140 & 0,088 \\
\hline Pernah & 16,7 & 21,3 & & \\
\hline Tidak pernah & 18,7 & 43,3 & & \\
\hline Antenatal Care (ANC) & & & $-0,035$ & 0,671 \\
\hline Dokter & 21,3 & 41,3 & & \\
\hline Bidan & 14,0 & 23,3 & & \\
\hline Cara persalinan & & & $-0,004$ & 0,958 \\
\hline SC & 14.0 & 25.3 & & \\
\hline Normal & 21.3 & 39.3 & & \\
\hline Tempat persalinan & & & $-0,040$ & 0,630 \\
\hline Rumah Sakit & 19,3 & 38,7 & & \\
\hline Puskesmas & 0 & 1,3 & & \\
\hline Klinik Bersalin & 16,0 & 22 & & \\
\hline Rumah Pribadi & 0 & 2,7 & & \\
\hline Penolong persalinan & & & $-0,034$ & 0,683 \\
\hline Dokter & 17.3 & 34 & & \\
\hline Bidan & 18 & 30.7 & & \\
\hline Berat badan lahir bayi & & & $-0,129$ & 0,117 \\
\hline BBLR & 1,3 & 7,3 & & \\
\hline Tidak BBLR & 34 & 573 & & \\
\hline Inisiasi menyusu dini (IMD) & & & $-0,039$ & 0,639 \\
\hline Ya & 15.3 & 30.7 & & \\
\hline Tidak & 20 & 34 & & \\
\hline Rawat gabung & & & 0,98 & 0,231 \\
\hline $\mathrm{Ya}$ & 26,7 & 42,7 & & \\
\hline Tidak & 8,7 & 22,0 & & \\
\hline Pemberian susu formula di & & & & \\
\hline instansi pelayanan kesehatan & & & $-0,335$ & 0,000 \\
\hline Ya & 11,3 & 43,3 & & \\
\hline Tidak & 24,0 & 21,3 & & \\
\hline $\begin{array}{l}\text { Riwayat rawat inap anak saat } \\
\text { berusia } 0-6 \text { bulan }\end{array}$ & & & $-0,092$ & 0,262 \\
\hline Pernah & 4,7 & 13,3 & & \\
\hline Tidak pernah & 30,7 & 51,3 & & \\
\hline Permasalahan menyusui dan & & & & \\
\hline kunjungan ke klinik laktasi & & & 0,249 & 0,002 \\
\hline Tidak pernah & 24,0 & 26,0 & & \\
\hline Pernah dan & 4,0 & 14,0 & & \\
\hline Konsultasi & 7,3 & 24,7 & & \\
\hline $\begin{array}{l}\text { Pernah tapi tidak } \\
\text { konsultasi }\end{array}$ & & & & \\
\hline Pemberian MPASI pada bayi usia & & & & \\
\hline$<6$ bulan & & & $-0,710$ & 0,000 \\
\hline Ya & 0 & 48 & & \\
\hline Tidak & 35,3 & 16,7 & & \\
\hline Pemakaian empeng (pacifier) & & & $-0,189$ & 0,020 \\
\hline Ya & 7 & 8,7 & & \\
\hline Tidak & 34,7 & 56 & & \\
\hline
\end{tabular}

Responden yang memberikan ASI eksklusif berdasarkan faktor psikososial, jumlah terbesar didapatkan pada kelompok yang memilki keinginan kuat memberikan ASI eksklusif $(35,3 \%)$, keyakinan kuat memberikan ASI eksklusif (28\%), memilki persepsi baik tentang kepuasaan bayi saat menyusu $(32,7 \%)$, mendapatkan dukungan kuat dari suami $(34,7 \%)$, dan orang tua $(28,0 \%)$. Keyakinan ibu yang kuat, persepsi kepuasan menyusui dan dukungan suami maupun orang tua tersebut mempunyai korelasi positif yang signifikan dengan keberhasilan ASI eksklusif.

Tabel 3. Hubungan faktor psikososial dengan keberhasilan ASI eksklusif

\begin{tabular}{|c|c|c|c|c|}
\hline \multirow[t]{2}{*}{ Faktor Psikososial } & \multicolumn{2}{|c|}{$\begin{array}{l}\text { ASI Eksklusif } \\
(\%)\end{array}$} & \multirow{2}{*}{$\begin{array}{l}\text { Korelasi } \\
\text { Spearman }\end{array}$} & \multirow[t]{2}{*}{$p$} \\
\hline & $\mathrm{Ya}$ & Tidak & & \\
\hline \multicolumn{5}{|l|}{ Keinginan ibu memberikan ASI eksklusif } \\
\hline Ya & & & 0,306 & 0,000 \\
\hline \multirow[t]{2}{*}{ Tidak } & 35,3 & 50 & & \\
\hline & 0 & 14,7 & & \\
\hline Keyakinan ibu terhadap menyusui & & & 0,263 & 0,001 \\
\hline Keyakinan kuat & 28,0 & 34 & & \\
\hline Keyakinan tidak kuat & 7,3 & 30,7 & & \\
\hline \multicolumn{3}{|c|}{$\begin{array}{l}\text { Persepsi ibu tentang kepuasan bayi saat } \\
\text { menyusui }\end{array}$} & 0,362 & 0,001 \\
\hline Tampak puas & 32,7 & 37,3 & & \\
\hline Tidak tampak puas & 2,7 & 27,3 & & \\
\hline \multicolumn{5}{|c|}{ Dukungan suami terhadap pemberian ASI } \\
\hline & & & 0,318 & 0000 \\
\hline Dukungan kuat & 34,7 & 46,7 & & \\
\hline Dukungan tidak kuat & 0,7 & 18,0 & & \\
\hline \multicolumn{5}{|c|}{ Dukungan orang tua ibu terhadap } \\
\hline Dukungan kuat & 28,0 & 32,0 & & \\
\hline Dukungan tidak kuat & 7,3 & 32,7 & & \\
\hline
\end{tabular}

\section{DISKUSI}

\section{Faktor Sosiodemografik}

Faktor sosiodemografik yang memilki hubungan bermakna dengan keberhasilan ibu memberikan ASI eksklusif adalah usia ibu dan status pekerjaan ibu. Dua faktor ini memilki hubungan negatif dengan keberhasilan ibu memberikan ASI eksklusif. Hasil menunjukkan semakin bertambah usia ibu meningkatkan frekuensi kegagalan pemberian ASI eksklusif. Meskipun hasil ini berbeda dengan beberapa penelitian tentang ASI eksklusif di Australia (4), Kanada (7), dan Cina (8), tetapi hasil di Lamongan ini memilki kesamaan dengan hasil penelitian di Nigeria (5). Ogunlesi memberikan kesimpulan bahwa semakin bertambah usia ibu tidak meningkatkan kualitas pemberian ASI kepada bayinya(5). Pola pengasuhan anak yang tradisional, diajarkan secara turun temurun dari orang tua ibu, tidak meningkatkan pengetahuan ibu terhadap pola pemberian ASI eksklusif (5).

Status pekerjaan ibu memilki hubungan negatif yang bermakna terhadap keberhasilan ibu memberikan ASI eksklusif. Hasil ini menunjukkan bahwa ibu yang bekerja meningkatkan frekuensi kegagalan pemberian ASI eksklusif. Hasil ini tidak berbeda dengan beberapa penelitian tentang ASI eksklusif di berbagai negara (4,710). Ibu yang bekerja akan menghadapi beberapa kendala dalam memberikan ASI eksklusif kepada bayinya, antara lain: alokasi waktu, kualitas kebersamaan dengan bayi, beban kerja, stres, dan keyakinan ibu untuk memberikan ASI eksklusif akan terpengaruh. Ibu yang bekerja memilki keyakinan yang rendah untuk dapat memberikan ASI 
eksklusif. Kondisi ini semakin diperburuk dengan UU No. 13 Tahun 2003 tentang Ketenagakerjaan yang berlaku di Indonesia. Pasal 82 dalam UU ini secara eksplisit memuat, "Pekerja/ buruh perempuan berhak memperoleh istirahat selama 1,5 (satu setengah) bulan sebelum saat melahirkan anak dan 1,5 (satu setengah) bulan sesudah melahirkan menurut perhitungan dokter kandungan atau bidan". Hal ini jelas tidak sejalan dengan rekomendasi World Health Organization yang mensyaratkan pemberian ASI eksklusif selama 6 bulan.

\section{Faktor Pre/Post Natal}

Dari lima belas faktor pre/postnatal yang dievaluasi dalam penelitian ini, faktor pemberian susu formula selama perawatan post partum di instansi pelayanan kesehatan, permasalahan menyusui dan kunjungan ke klinik laktasi, pemberian MPASI pada bayi usia $<6$ bulan, dan pemakaian empeng (pacifier) menunjukkan hubungan yang bermakna dengan keberhasilan ibu memberikan ASI eksklusif. Suplementasi susu formula selama perawatan post partum di instansi pelayanan kesehatan secara konsisten dan signifikan memilki hubungan negatif terhadap keberhasilan pemberian ASI eksklusif. Hasil penelitian di Lamongan dengan analisa bivariate ( $r=-$ $0,335, p=0,000)$ memberikan hasil yang tidak berbeda dengan penelitian Forster et al (4), Riva et al (11), Hornell et al (12), dan Semenic et al (7). Pemberian suplementasi susu formula selama perawatan post partum telah lama diketahui dapat mengganggu skema pemberian ASI. Pemberian susu formula akan mempengaruhi produksi air susu ibu dan kemampuan bayi menyusu payudara ibu (13). Pemberian susu formula di instansi pelayanan kesehatan akan semakin memberikan pengaruh negatif terhadap ibu yang memilki permasalahan menyusui post partum dan menurunkan keyakinan ibu untuk dapat memberikan ASI eksklusif $(7,11)$.

Ibu yang tidak pernah memilki permasalahan menyusui memilki peluang untuk berhasil memberikan ASI eksklusif kepada bayinya. Ibu yang tidak pernah mengalami permasalahan dalam menyusui bayinya akan memiliki keyakinan kuat (breastfeeding self-efficacy) untuk memberikan ASI eksklusif. Dari data penelitian ini juga dapat dilihat, dari 53 orang $(35,3 \%)$ yang berhasil memberikan ASI eksklusif, 42 orang $(79,2 \%)$ di antaranya tidak pernah memiliki masalah menyusui atau pernah memilki masalah menyusui dan berkonsultasi ke klinik

\section{DAFTAR PUSTAKA}

1. Habicht JP and WHO Expert Consultation. Expert Consultation on the Optimal Duration of Exclusive Breastfeeding: The Process, Recommendations, and Challenge the Future. Conclusions and Recommendations. Advances in Experimental Medicine and Biology. 2004; 554: 79-87.

2. Harnowo PA. Hanya 33,6\% Bayi di Indonesia yang Dapat ASI Eksklusif. (Online) 2012. http://health.detik.com/read/2012/09/19/132344/ 2025874/764/hanya-336-bayi-di-indonesia-yangdapat-asi-eksklusif.

3. United Nations. United Nations: Supporting Health Related MDGs. (Online) 2013 . http://www.un.org/apps/news/story.asp?NewsID=4 4265\&Cr=malaria\&Cr1=\#.UVakORezKuJ. laktasi.

Pemberian MPASI dini akan meningkatkan kegagalan pemberian ASI eksklusif. Penelitian Freeman et al (14) dan Haiek et al (15) menunjukkan kesimpulan yang sama, pemberian MPASI dini kontra produktif terhadap upaya pemberian ASI eksklusif di banyak negara berkembang (16-19). Hasil di Lamongan ini juga semakin menambah bukti masih banyak orang tua yang memberikan MPASI pada bayi usia $<6$ bulan (48\%). Pemakaian empeng (pacifier) tidak bisa lagi dianggap hal lumrah dan sepele oleh kebanyakan orang tua. Data dari penelitian ini konsisten dengan hasil penelitian di Cina (8), Inggris (20) dan Italia (11) yang menunjukkan pemakain empeng (pacifier) berhubungan dengan kegagalan pemberian ASI eksklusif.

\section{Faktor Psikososial}

Hasil penelitian ini menunjukkan keinginan dan keyakinan ibu yang kuat untuk memberikan ASI eksklusif didapatkan pada sebagian besar ibu yang berhasil memberikan ASI eksklusif. Keyakinan atau kepercayaan diri ibu yang kuat merupakan faktor determinan yang penting terhadap keberhasilan pemberian ASI eksklusif (21-22). Keyakinan atau kepercayaan diri ibu yang kuat mendorong ibu untuk mempelajari hal-hal baru termasuk teknik menyusui yang belum dikuasai benar oleh ibu primipara. Beberapa penelitian sebelumnya melaporkan ibu dengan keyakinan yang kuat, lebih sedikit memilki permasalahan menyusui, persepsi yang baik tentang kepuasaan bayi saat menyusu, dan berupaya aktif memperoleh informasi tentang laktasi (4). Social support system termasuk dukungan dari suami dan orang tua ibu memilki pengaruh yang signifikan terhadap keberhasilan ibu memberikan ASI eksklusif. Penelitian Semenic et al menunjukkan bahwa dukungan suami dan orang tua ibu adalah support system yang mendorong ibu menginisiasi dan mempertahankan laktasi, terutama ibu-ibu baru yang akan memulai laktasi (8).

Temuan penelitian ini mendukung fakta masih rendahnya angka ASI eksklusif (35,3\%). Pemberian MPASI dini merupakan faktor determinan kuat yang menghambat keberhasilan ASI eksklusif. Keyakinan dan kepercayaan diri ibu yang kuat merupakan faktor determinan penting yang mendorong keberhasilan ASI eksklusif.

4. Forster DA, McLachlan HL, and Lumley J. Factors Associated With Breastfeeding at Six Months Postpartum in a Group of Australian Women. International Breastfeeding Journal. 2006; 1: 18.

5. Ogunlesi TA. Maternal Socio-Demographic Factors Influencing The Initiation and Exclusivity of Breastfeeding in a Nigerian Semi-Urban Setting. Maternal Child Health Journal. 2010; 14(3): 459-465.

6. Suyatno. Menghitung Besar Sampel Penelitian Kesehatan Masyarakat. (Online) 2010. http://www.suyatno.blog.undip.ac.id.

7. Semenic S, Loiselle C, and Gottlieb L. Slovin's Formula Sampling Techniques. Research in Nursing \& Health. 2008; 31: 428-441.

8. Xu F, Binns $C$, Zheng $S$, Wang $Y$, Zhao $Y$, and Lee A. Determinants of Exclusive Breastfeeding Duration in 
Xinjiang-China. Asia Pacific Journal of Clinical Nutrition. 2007; 16(2): 316-321

9. Bertini G, Perugi S, Dani C, Pezzati M, Tronchin M, and Rubaltelli FF. Maternal Education and the Incidence and Duration of Breastfeeding: A Prospective Study. Journal of Pediatric Gastroenterology and Nutrition. 2003; 37(4): 447-452

10. Cham SK and Asirvatham CV. Feeding Practices of Infants Delivered in a District Hospital During the Implementation of Baby Friendly Hospital Initiative. Medical Journal of Malaysia. 2001; 56(1): 71-76.

11. Riva E, Banderali G, Agostoni C, Silano M, Radaelli G, and Giovannini M. Factors Associated with Initiation and Duration of Breastfeeding in Italy. Acta Paediatrica. 1999; 88(4): 411-415.

12. Hornell A, Hofvander Y, and Kylberg E. Solids and Formula: Association with Pattern and Duration of Breastfeeding. Pediatrics. 2001; 107(3): e38.

13. World Health Organization. Evidence for the Ten Steps to Successful Breastfeeding. Geneva: World Health and Development; 1998.

14. Freeman V, van't Hof $\mathrm{M}$, and Haschke F. Patterns of Milk and Food Intake in Infants from Birth to 36 Months: The Euro-Growth Study. Journal of Pediatric Gastroenterology and Nutrition. 2000; 31(1): S76-S85

15. Haiek LN, Gauthier DL, Brosseau D, and Rocheleau L. Understanding Breastfeeding Behavior: Rates and Shifts in Patterns in Quebec. Journal of Human Lactation. 2007; 23(1): 24-31.
16. Agampodi SB, Agampodi TC, and Piyaseeli UK. Breastfeeding Practices in a Public Health Field Practice Area in Sri Lanka: A Survival Analysis. International Breastfeeding Journal. 2007; 2: 13.

17. Aghaji MN. Exclusive Breastfeeding Practices And Associated Factors In Enugu, Nigeria. West African Journal of Medicine. 2002; 21(1): 66-69

18. Dubois L and Girard M. Social Determinants of Initiation, Duration and Exclusivity of Breastfeeding at the Population Level; The Results of the Longitudinal Study of Child Development in Quebec (ELDEQ 1998-2002). Canadian Journal of Public Health. 2003; 94(4): 300-305.

19. Salami LI. Factors Influencing Breastfeeding Practices in Edo State, Nigeria. (Online) 2008. http://ajfand.net/issue-XI-files/pdfs/SALAMI _1680.pdf.

20. Clements MS, Mitchell EA, Wright SP, Esmail A, Jones $\mathrm{DR}$, and Ford RPK. Influences on Breastfeeding in Southeast England. Acta Paediatrica. 1997. 86(1): 5156.

21. Blyth R, Creedy D, Dennis CL, Moyle W, Pratt J, and De Vries S. Effect of Maternal Confidence on Breastfeeding Duration: An Application of Breastfeeding Self-Efficacy Theory. Birth. 2002; 29(4): 278-284.

22. Dennis CL. Theoretical Underpinnings of Breastfeeding Confidence: A Self-Efficacy Framework. Journal of Human Lactation. 1999; 15(3): 195-201. 